\title{
Análise Comparativa do Perfil de Crianças em Acolhimento Institucional nos Anos de 2004 e 2009
}

\author{
Lília Iêda Chaves Cavalcante \\ Celina Maria Colino Magalhães \\ Daniela Castro dos Reis \\ Universidade Federal do Pará \\ Belém, PA, Brasil
}

\begin{abstract}
RESUMO
O estudo apresenta uma análise comparativa dos aspectos que caracterizaram a população infantil atendida em uma instituição de acolhimento na Região Metropolitana de Belém-Pará, nos anos de 2004 (n=287) e 2009 (n=249). Foram comparadas variáveis referentes às características sociodemográficas das crianças, ao motivo do acolhimento, a idade à entrada na instituição e o tempo de permanência. Os resultados mostram que o perfil da população atendida sofreu alterações importantes: em cinco anos, aumentou a idade em que as crianças ingressaram na instituição, o que pode evitar ou atenuar as sequelas geradas pela privação do cuidado parental, porém também estendeu o tempo que elas se mantiveram atendidas pelo serviço, sendo este um aspecto que agrava a sua condição de vulnerabilidade. Estes dados corroboram o argumento de que é necessário acompanhar ao longo do tempo estas e outras características dessa população infantil, para adequar a gestão dos serviços de acolhimento às suas demandas desenvolvimentais.
\end{abstract}

Palavras-chave: Abrigo. Acolhimento institucional. Crianças abrigadas. Desenvolvimento infantil. Vulnerabilidade. Características da população.

\begin{abstract}
Comparative Analysis of the Profile of Children in Institutional Care the Years of 2004 and 2009

The study presents a comparative analysis of the aspects that characterized the child population served in a host institution in the metropolitan region of Belém, Pará, the years of $2004(n=287)$ and $2009(n=249)$. Variables were compared regarding sociodemographic characteristics of children, the reason for the host, age at entry into the institution and length of stay. The results show that the profile of the population served has undergone major changes: in five years, increased the age at which children entered the institution, which may prevent or mitigate the consequences generated by deprivation of parental care, but also extended the time they remained satisfied by the service, and this is one aspect that aggravates their condition of vulnerability. These data support the argument that it is necessary to monitor over time these and other characteristics of this population, to tailor the management of care services to their developmental demands.
\end{abstract}

Keywords: Shelters. Sheltered children. Childhood development. Vulnerability. Characteristics of the population.

\section{RESUMEN}

Análisis Comparativo del Perfil de los Niños Internados en Instituciones en los Años de 2004 y 2009

El estudio presenta un análisis comparativo de los aspectos que caracterizan a la población infantil servido en un centro de acogida en la región metropolitana de Belém, Pará, en los años de 2004 ( $n=287)$ y 2009 (n=249). Las variables se compararon con respecto a las características sociodemográficas de los niños, el motivo de la acogida, la edad de ingreso en la institución y la duración de la estancia. Los resultados muestran que el perfil de la población atendida ha sufrido grandes cambios: en cinco años, el aumento de la edad en que los niños entraron en la institución, lo que puede prevenir o mitigar las consecuencias generadas por la privación de cuidados parentales, pero también se extiende el tiempo que siendo satisfecho por el servicio, y este es un aspecto que agrava su condición de vulnerabilidad. Estos datos apoyan el argumento de que es necesario controlar el paso del tiempo estas y otras características de esta población, para adaptar la gestión de los servicios de atención a sus demandas de desarrollo.

Palabras clave: Abrigos. Ninos abrigados. Desarrollo infantil. Vulnerabilidad. Características de la población. 


\section{INTRODUÇÃO}

Existem evidências de que a condição psicossocial de crianças de zero a três anos de idade tem hoje profundas implicações para a formulação de políticas públicas de atenção ao desenvolvimento na primeira infância, particularmente quando destinadas à proteção social dos mais vulneráveis à pobreza, à doença e à violência. É preciso investigar minunciosamente as características dessa população infantil e as condições em que tem ocorrido o seu acolhimento em instituições da rede socioassistencial, pois isso contribui para elucidar o contexto no qual cotidianamente são satisfeitas as necessidades de uma parcela ainda expressiva de crianças em situação de evidente vulnerabilidade (Scaramella, Neppl e Conger, 2008). Portanto, conhecer e monitorar a evolução das características pessoais de crianças encaminhadas a instituições infantis em seus anos iniciais de vida pode auxiliar na compreensão contextualizada do seu desenvolvimento biopsicossocial (Bronfenbrenner, 2011; Nelson, 2007).

As experiências acumuladas durante os períodos reconhecidos como de maior sensibilidade permitem organizar a estrutura física do cérebro da criança. Nessas condições, o cérebro estaria particularmente maleável e receptivo às demandas colocadas pelo ambiente social. Todavia, a capacidade de ajustar-se às pressões do meio externo leva a criança a elaborar e dar respostas que poderão conduzir a sua trajetória de forma a alcançar um desenvolvimento saudável e pleno em vários aspectos, ou mesmo potencialmente muito limitado por conta da sua submissão a condições sociofamiliares pobres em estímulos intelectuais e afetivos (Andrade, Santos, Bastos, Pedromônico, Almeida-Filho e Barreto, 2005).

Nos dias atuais, trabalha-se com evidências sólidas de que as atividades positivas que promovem o desenvolvimento saudável têm consequências benéficas para a criança em toda a sua vida (Halpern e Figueiras, 2004; Tarullo e Gunnar 2007). Nesse sentido, pesquisas vêm confirmar que as experiências que contribuem para o desenvolvimento atípico da criança ou aquém do socialmente desejado estão geralmente associadas ao como e o quanto o cérebro se desenvolve nessa fase, ainda que em condições hostis (Vegas e Santibáñez, 2010). Em contrapartida, outros estudos apontam que muito pode ser feito para superar as situações adversas que agravam o seu estado de vulnerabilidade e os efeitos prejudiciais das desvantagens socioeconômicas para a criança (Brancalhone, Fogo e Williams, 2004; Calamante, 2007; Habigzang, Koller, Azevedo, e Machado, 2005; Paiva, Lima, Lima e Eickmann, 2010; Rede Nacional Primeira Infância, 2010).
A alternativa para essa realidade adversa pode ser a) propiciar à criança experiências positivas capazes de favorecer o desenvolvimento do cérebro, sobretudo nos três primeiros anos da infância; b) incentivar interações mútuas entre a criança e o ambiente no qual está inserida; e c) enfrentar os efeitos negativos da estimulação deficiente e dos cuidados negligentes na família ou em instituições infantis, como creches e instituições de acolhimento. A perspectiva ecológica na pesquisa do desenvolvimento humano (Bronfenbrenner, 2011), permite predizer estes e outros recursos, estímulos e oportunidades que podem agir no sentido de proteger a infância ameaçada pela pobreza e o abandono. Este modelo teórico possibilita uma compreensão mais complexa e multideterminada da pobreza, e seus efeitos para o desenvolvimento dos indivíduos e da sociedade dela fazem parte, tornando possível preveni-los e revertê-los em condições específicas (Barros, Carvalho e Franco, 2006)

Pesquisas recentes apontam que o quadro de pobreza e vulnerabilidade social das famílias desempenha, em qualquer parte do mundo, um papel importante nas condições colocadas à aquisição de habilidades e competências socialmente valorizadas na vida adulta, mas aprendidas desde a infância (Paiva et al., 2010; Scaramella et al., 2008). Desse modo, saber distinguir e avaliar as implicações decorrentes das características pessoais e sociais das crianças em situação de pobreza e vulnerabilidade e como elas se refletem nas experiências que resultaram no seu processo de acolhimento institucional, constitui-se em objeto de pesquisa com nítida relevância social e científica, para pesquisadores da área da psicologia e afins (Bronfenbrenner, 2011). Afinal, estudos realizados nas últimas décadas têm explorado com relativa frequência os efeitos das características de crianças que nasceram e cresceram em situação de vulnerabilidade social para o desenvolvimento inicial, principalmente as que foram acolhidas em instituições asilares ainda que temporariamente, mas que, em decorrência disso, permaneceram afastadas da convivência com seus pais e/ou responsável por motivos associados à privação emocional e/ou da pobreza em níveis extremos (Dozier, Zeanah, Wallin e Shauffer, 2012; Roy e Rutter, 2006; Siqueira e Dell'Aglio, 2006; Tarullo e Gunnar, 2007; Wiik, Loman, Ryzin, Armstrong, Essex, Pollak e Gunnar, 2010).

Com base em evidências assumidas por análises de casos clínicos e estudos psicométricos, admite-se que crianças que vivem nessas condições ecológicas desfavoráveis podem não conseguir alcançar os resultados esperados em sua trajetória de desenvolvimento, dificultando seu amadurecimento físico, cognitivo e 
socioemocional (Beckett, Maughan, Rutter, Castle, Colvert, Groothues, Kreppner, Stevens, O'Connor, e Sonuga-Barke, 2006). Esse quadro reforça a preocupação quanto aos resultados do desenvolvimento observados na primeira infância e suas consequências para toda a vida, afetando a produtividade e a capacidade de realização do indivíduo adulto (renda futura, saúde integral, disposição para o trabalho e longevidade).

A literatura fortalece o argumento de que crianças institucionalizadas são quase que sinônimo de crianças pobres ou socialmente vulneráveis (Bernal, 2004). Isso se deve às evidências de que essas crianças têm sido descritas como provenientes de famílias com renda, moradia e escolaridade precárias, muitas vezes expostas precoce e prolongadamente a toda sorte de privações e maus tratos (Cavalcante, 2008; Cavalcante, Costa e Magalhães, 2012; IPEA, 2004; Lewandowski, De Antoni, Koller e Piccinini, 2002; Habigzang et al., 2005; Morais, Leitão, Koller e Campos, 2004; Serrano, 2008; Sigal, Perry, Rossignol, e Ouimet, 2003). Essas pesquisas mostram que a combinação entre pobreza, violência doméstica e consumo abusivo do álcool e outras drogas, pelos pais, se impõem à criança como fator de risco ao seu desenvolvimento, sobretudo daquelas que vivem em famílias multiproblemáticas. Esses e outros indicadores de vulnerabilidade social expressam o nível de deterioração das condições gerais de vida da população infantil em um dado contexto, que podem criar situações ecológicas propícias ao descumprimento pelos pais das funções parentais: garantir proteção à criança contra qualquer forma de abandono e violência.

Nas condições em que os pais e demais responsáveis pela criança falharam e/ou se omitiram em relação às funções parentais de sustento, criação e educação infantil, o acolhimento institucional deve funcionar como medida de proteção social (Dozier et al., 2012). Entretanto, o aspecto protetivo dessa medida perde força quando a sua permanência sob as condições ecológicas geralmente oferecidas por essa modalidade de acolhimento e o padrão de cuidado institucional se prolonga no tempo, ultrapassando o limite estabelecido de dois anos.

Sabe-se, hoje, que a colocação precoce e a permanência prolongada da criança em instituições de acolhimento, são medidas que devem ser igualmente evitadas quando se almeja o desenvolvimento inicial da forma mais plena possível (Cavalcante, Magalhães e Pontes, 2007). Contudo, também deve ser evitado o acolhimento de crianças motivado por situações de risco decorrentes somente da pobreza e da precariedade da renda de suas famílias. De acordo com o Estatuto da Criança e do Adolescente (ECA), a pobreza não pode se constituir em motivo suficiente para retirada de uma criança do convívio com seus pais e sua manutenção em uma instituição de longa permanência.

Diante dessa e outras questões que cercam o debate sobre o tema, esta pesquisa teve como objetivo realizar análise comparativa do perfil das crianças acolhidas por uma instituição infantil e dos aspectos envolvidos nesse processo, tomando como referência os atendimentos realizados em dois períodos de tempo: 2004 e 2009. A partir dos resultados obtidos far-se-á considerações sobre permanências e/ou mudanças nos indicadores pesquisados, apontado quais as principais alterações observadas no perfil das duas amostras examinadas nesse intervalo de cinco anos.

\section{MÉTODO}

\section{Informantes}

$\mathrm{Na}$ fase inicial da pesquisa, participaram cinco técnicos (duas assistentes sociais, uma psicóloga, uma pedagoga e uma enfermeira) que forneceram e/ou complementaram dados sobre diferentes aspectos da vida de 287 crianças acolhidas no ano de 2004, obtidos previamente a partir de consulta a documentos fornecidos pela instituição. Cinco anos depois, outro levantamento envolveu uma equipe técnica composta por 15 profissionais, sendo quatro assistentes sociais, duas psicólogas, uma pedagoga, uma enfermeira e mais sete auxiliares de enfermagem, que disponibilizaram informações referentes às crianças atendidas no ano de 2009 (n=249), na mesma instituição e com igual procedimento.

\section{Ambiente}

A pesquisa foi realizada na instituição de acolhimento infantil considerada como o principal abrigo do estado do Pará, localizada na Região Metropolitana de Belém.

\section{Instrumento e Materiais}

Nos períodos investigados, os anos de 2004 e 2009, utilizou-se como instrumento de registro a ficha elaborada por Cavalcante (2008) com base em estudo anterior de Weber e Kossobudzki (1996) sobre a condição psicossocial de crianças que viviam em abrigos e instituições similares. $\mathrm{O}$ instrumento utilizado foi composto por perguntas estruturadas com múltiplas alternativas de resposta, organizadas em torno dos seguintes eixos: identificação pessoal (10 itens), estrutura familiar (19 itens), histórico de institucionalização (30 itens), situação sociojurídica atual (19 itens) e saúde da criança (16 itens).

A coleta se deu diretamente nos prontuários das crianças. Os documentos consultados foram: Estudo 
Social (dados sobre a composição familiar, condições de moradia, perfil dos pais e/ou responsáveis), Declaração de Nascidos Vivos (informações sobre a gestação, a parturiente, o parto, as características do recém-nascido), Prontuário Médico (anotações sobre condição geral de saúde ao ingresso no abrigo e ao longo da sua permanência) e Termo de Encaminhamento do Conselho Tutelar (relatos sobre a condição sociojurídica da criança). Aliado à coleta em fontes documentais, realizou-se entrevista semiestruturada com técnicos e outros funcionários para o levantamento de informações necessárias ao preenchimento de eventuais lacunas no material examinado.

\section{Procedimento}

Nos dois períodos o levantamento das informações foi feito a partir de autorização do Judiciário, que permitiu o acesso aos prontuários e à equipe técnica. Os estudos foram aprovados por Comitês de Ética para Pesquisas com Seres Humanos da Universidade Federal do Pará (processos $n^{\circ} 062 / 2004$ - CEP/MMT/ UFPA e $n^{\circ}$ 018/2008 - CEP/ICS/UFPA).

A seleção do material examinado obedeceu a critérios como legitimidade (apenas documentos oficiais) e confiabilidade (exceto certidões com rasuras ou ilegíveis e anotações informais). A definição das variáveis, categorias e unidades de análise neste estudo orientou a transcrição e a organização dos dados coletados, e depois o seu tratamento estatístico, utilizando-se para tanto planilhas eletrônicas do programa Excel, da Microsoft. O sistema de descrição dos resultados foi estruturado a partir das seguintes unidades: descritores das crianças (sexo e idade) e do seu processo de acolhimento (convívio com a família de origem, reconhecimento da paternidade em documento civil, motivo e tempo de permanência na instituição).

\section{RESULTADOS}

A análise comparativa dos resultados obtidos nos dois momentos temporais permitiu identificar semelhanças e diferenças no perfil das crianças pesquisadas, sobretudo traços predominantes na sua situação sociofamiliar, e nas condições em que ocorreu o acolhimento infantil.

Entre os principais resultados, verificou-se que, no ano de 2004, a instituição acolheu mais crianças do sexo feminino $(51,22 \%)$ do que do masculino (48,78\%), enquanto que, em 2009, cinco anos depois, foram encontrados mais meninos $(54,62 \%)$ do que meninas $(45,38 \%)$. No que se refere especificamente à idade em que deram entrada na instituição como medida sociojurídica de proteção, excepcional e provisória, constatou-se que, na primeira amostra, a criança mais nova havia nascido há apenas um dia e a menos jovem há dez anos. À época, $34,84 \%$ das crianças se encontravam no primeiro ano de vida, sendo que, quando se considerou a frequência da faixa-etária de zero a três anos, este percentual elevou-se e passou a representar 65,85\%. Assim, quase dois terços das crianças estavam na primeira infância quando foram levadas a viver em uma instituição infantil. Em 2009, um percentual menor de crianças $(9,63 \%)$ estava no primeiro ano de vida ou na faixa-etária de zero a três anos $(44,98 \%)$. Este dado confirma que, no intervalo de cinco anos considerado pela pesquisa, houve uma redução no número de recém-nascidos acolhidos pela instituição logo após o parto, assim como de crianças que se encontravam no primeiro ano.

Quando ao cruzamento das variáveis sexo e idade da criança no momento do seu ingresso na instituição, observou-se que a distribuição de meninos e meninas por faixa-etária apresentou mais convergências do que divergências na comparação entre os dados de 2004 e 2009. A Tabela 1 mostra que, no primeiro ano de vida, as crianças do sexo masculino representavam a maioria na população acolhida pela instituição em ambos os levantamentos, assim como na faixa etária que reúne aquelas com idade de 13 e 24 meses. Por sua vez, as crianças do sexo feminino predominaram nas faixas etárias que se estendiam dos três aos cinco anos. Nos demais intervalos, meninos e meninas se revezaram nas primeiras colocações, conforme Tabela 1.

\section{TABELA 1}

Percentual de crianças por sexo e idade na data de registra do seu ingresso na instituição, nos anos de 2004 e 2009

\begin{tabular}{rcccc}
\hline \multirow{2}{*}{ Categorias } & \multicolumn{2}{c}{$2004(n=287)$} & \multicolumn{2}{c}{$2009(n=249)$} \\
\cline { 2 - 5 } & Feminino & Masculino & Feminino & Masculino \\
\hline 0 a 12 meses & 16,45 & 18,25 & 7,07 & 11,76 \\
13 a 24 meses & 13,2 & 18,25 & 17,71 & 19,86 \\
25 a 36 meses & 16,45 & 13,98 & 15,05 & 17,64 \\
37 a 48 meses & 11 & 9,2 & 19,47 & 17,64 \\
49 a 60 meses & 12,4 & 10,2 & 11,50 & 8,09 \\
61 a 72 meses & 14,5 & 11,17 & 7,9 & 10,3 \\
$>72$ meses & 16 & 18,95 & 21,3 & 14,71 \\
Total & 100 & 100 & 100 & 100 \\
\hline
\end{tabular}

No ano de 2004, foi apurado que em $66,91 \%$ dos casos analisados a criança convivia com sua família de origem, entendendo-a como a comunidade formada pelos pais $(13,24 \%)$ ou por qualquer um deles, seja a mãe $(49,14 \%)$, seja o pai $(4,53 \%)$. De qualquer forma identificou-se presença do pai e/ou da mãe em seu ambiente imediato, ainda que este estudo revele que o principal responsável pelas rotinas de cuidado 
e o custeio das despesas com o sustento e educação infantil (alimentação, vestuário, despesas escolares, entre outras) seja majoritariamente a mulher. No ano de 2009, os dados demonstraram que, em relação ao primeiro levantamento dobrou o percentual de crianças que conviviam com a mãe e o pai em uma mesma casa, passando de $13,24 \%$, em 2004, para $38,56 \%$, no ano de 2009. Consequentemente houve uma redução no percentual de crianças que moravam somente com a mãe: variou de 49,14\% (2004) para 23,30\% (2009).

Os dados mostraram também que é expressivo e crescente o número de crianças que não dispunham do reconhecimento da paternidade em documento civil, representando $28,57 \%$, em 2004 , e $34,94 \%$, no ano de 2009. Comparativamente, pode-se concluir que aumentou o número de crianças que não conviviam com o pai antes de dar entrada na instituição nem que tiveram a sua paternidade legalmente reconhecida pelo mesmo.

Os resultados referentes ao motivo de entrada no serviço de acolhimento institucional revelaram que em $40,41 \%$ dos casos de 2004, as crianças foram encaminhadas à instituição por um conjunto de fatores relacionados à privação material e emocional. Do total da amostra, 59,59\% das crianças foram encaminhadas à instituição por situações que envolviam crises e dificuldades experimentadas por sua família de origem, seja de forma independente, ou em associação com outros. No ano de 2009, os dados sugerem que os motivos apontados para apoiar ou não a decisão de acolher institucionalmente a criança não foram diferentes do período anterior, como mostra a Tabela 2.
Os resultados de 2004 e 2009 demonstraram que a negligência familiar, seja como motivo único para o acolhimento da criança $(35,89 \%$ e $6,82 \%)$ seja quando relacionada a outras vicissitudes experimentadas pela família (63,06\% e 51\%), foi uma das categorias com maior frequência. A Tabela 2 mostra que outros motivos foram igualmente citados nos prontuários examinados na instituição: o abandono familiar, a dependência do álcool e outras drogas por parte dos pais e/ou responsáveis, além da violência física e sexual que atinge a criança, sobretudo no ambiente doméstico.

Outro aspecto que deve ser considerado é que, contrariando o que diz o ECA, a pobreza foi considerada como motivo que serviu como justificativa para muitos dos casos analisados. Na primeira amostra, esta categoria representou $24,1 \%$ dos casos. Na amostra mais recente, este traço da condição sociofamiliar das crianças, apesar de supostamente comum nessa população, foi citado como motivo para a sua longa permanência na instituição em $16,86 \%$ do total de casos examinados.

Para descrição do tempo de permanência da criança na instituição foi considerado tanto o período atual (referente a um único e/ou último acolhimento) quanto total (relativo a todos os ingressos anteriores no abrigo). Os resultados mostraram que os percentuais que sofreram acréscimos em cinco anos correspondem a categorias que indicam um tempo de convivência maior da criança no ambiente institucional, principalmente entre aquelas cujo período de acolhimento foi superior a cinco meses e inferior a três anos completos, conforme demonstra a Tabela 3.

TABELA 2

Percentual de crianças de acordo com a justificativa mencionada para o acolhimento institucional, nos anos de 2004 e 2009

\begin{tabular}{|c|c|c|c|c|}
\hline \multirow{2}{*}{ Categorias } & \multicolumn{2}{|c|}{$2004(n=287)$} & \multicolumn{2}{|c|}{$2009(n=249)$} \\
\hline & Motivo único & Motivo associado & Motivo único & Motivo associado \\
\hline Abandono & 9,76 & 24,43 & 12,44 & 45,38 \\
\hline Deficiência física ou mental dos pais & 2,79 & 4,18 & 0 & 0 \\
\hline Dependência do álcool e outras drogas dos pais & 0,69 & 14,63 & 12,04 & 26,1 \\
\hline Doença física e/ou mental dos pais & 0,35 & 1,39 & 0,4 & 5,22 \\
\hline Impedimento judicial & 1,74 & 6,62 & 0 & 0 \\
\hline Negligência familiar & 35,89 & 63,06 & 6,82 & 51 \\
\hline Pobreza e vulnerabilidade social dos pais & 3,49 & 6,69 & 1,2 & 16,86 \\
\hline Situação de rua & 0,35 & 1,74 & 0,4 & 1,6 \\
\hline Violência física & 2,79 & 13,24 & 1,2 & 8,03 \\
\hline Violência sexual & 0,35 & 1,74 & 1,2 & 3,21 \\
\hline Outros motivos para o acolhimento & 1,39 & 5,22 & 6,42 & 23,69 \\
\hline
\end{tabular}


TABELA 3

Caracterização das crianças acolhidas quanto ao tempo de permanência atual e total na instituição

\begin{tabular}{lcccc}
\hline \multirow{2}{*}{$\begin{array}{c}\text { Tempo de } \\
\text { permanência no abrigo }\end{array}$} & \multicolumn{2}{c}{$2004(n=287)$} & \multicolumn{2}{c}{$2009(n=249)$} \\
\cline { 2 - 5 } < 1 mês & Atual & Total & Atual & Total \\
\hline 1 a 6 meses & 50,52 & 49,82 & 37,75 & 35,75 \\
7 a 12 meses & 7,67 & 31,36 & 28,91 & 27,31 \\
13 a 24 meses & 3,14 & 3,48 & 18,48 & 18,07 \\
25 a 36 meses & 4,52 & 4,88 & 2,00 & 3,61 \\
> 36 meses & 1,04 & 1,04 & 1,61 & 1,61 \\
Total & 100 & 100 & 100 & 100 \\
\hline
\end{tabular}

No que se refere à variável de tempo de permanên-cia da criança sob os cuidados da instituição, observou-se que, no primeiro levantamento, a maior parte nela esteve por um período de até 15 dias $(41,81 \%)$, assim como se verificou ser grande o número daquelas que se encontravam acolhidas por menos de três meses (70,04\%). Do total de 287 crianças, $8,7 \%$ faziam da instituição seu local de moradia por um período de tempo que oscilou de 13 meses até 66 meses. Em 2009, o quadro sofreu alteração e aumentou o tempo de exposição da criança às condições ecológicas da instituição: o percentual saltou de $8,7 \%$ para $14,86 \%$.

\section{DISCUSSÃO}

O conjunto dos dados apresentados neste artigo provoca uma série de reflexões sobre a prática tão antiga, quanto comum, de encaminhar para instituições de acolhimento crianças socialmente vulneráveis nos primeiros dias e meses de vida. Todavia, os dados deixam claro que, apesar de, em cinco anos, ter aumentado a idade em que a maior parte da população pesquisada deu entrada na instituição, caindo os percentuais referentes de $65,85 \%$ para $44,98 \%$, pode-se perceber que ainda é expressivo o número de crianças que segue exposto na primeira infância aos efeitos da institucionalização precoce, como tem sido advertido por pesquisadores sobre diferentes épocas.

Embora os dados tenham demonstrado que no intervalo de cinco anos houve uma diminuição de crianças que entraram na instituição nos primeiros anos de vida, este ainda é um aspecto que merece a preocupação de autoridades, profissionais e pesquisadores que atuam na esfera da política de proteção social à chamada infância em risco. Isso porque, conforme Sigal et al. (2003), quanto menor a idade da criança institucionalizada maior será a chance de vir a apresentar retardos e sequelas graves em seu desenvolvimento. Em contrapartida, quanto maior for o tempo passado em instituições que oferecem atendimento massificado e com poucos momentos de intimidade, maior é a possibilidade de a criança vir a sofrer os efeitos nocivos dessa experiência ao longo da vida.

Os resultados desta pesquisa demonstram que a quantidade de meses e anos passados em uma instituição é uma preocupação justa como mostra a literatura, pois um contingente numeroso de crianças foi acolhido por mais de dois anos, contrariando o que recomenda a legislação sobre o tema, apresentando esta variável oscilação positiva quando se comparou os dados de 2004 e 2009. Para estas crianças, em particular, a convivência em ambiente institucional por tão longo tempo e a experiência precoce da separação e/ou perda da figura de apego em uma fase considerada de maior sensibilidade para o desenvolvimento do cérebro, colocam a possibilidade de uma vida afetiva marcada por contínua sensação de insegurança e desamparo, além de déficits cognitivos e de habilidades sociais decorrentes de uma infância marcada desde o período intrauterino por fatores de privação material e emocional, como evidenciaram Wiik et al. (2010) e Dozier et al. (2012).

Por essa razão, este estudo não apenas dá o merecido destaque à variável tempo de permanência da criança no abrigo apontando inclusive a sua elevação no curso de cinco anos, como também demonstra que o período vivido longe de casa pelas crianças pesquisadas pode ser maior do que estimam as estatísticas obtidas. Nos casos em que crianças foram encaminhadas à instituição mais de uma vez, parece lógico supor que a quantidade de tempo passado sem o convívio com seus cuidadores primários pode sofrer algum acréscimo à medida que se computam os dias e os meses referentes à ocorrência de ingressos anteriores na instituição.

Em contrapartida, constatou-se que 49,82\% (2004) e $35,75 \%$ (2009) das crianças ficaram no abrigo por um período superior a um mês e deram entrada mais de uma vez no serviço de acolhimento. As razões que explicam este fato podem ser muitas, mas há sempre a hipótese de que a colocação em abrigo, que deveria funcionar como medida de proteção, ficando restrita às situações em que há efetivamente risco à vida e à segurança da criança, tem sido aplicada em casos que poderiam ter sido atendidos por outro tipo de instituição, que está habilitada ao acolhimento emergencial de crianças e adolescentes por até 72 horas. Por outro lado, esta pesquisa revelou um percentual alto de crianças na primeira infância acolhidas no abrigo como local de moradia há mais de um ano e um mês e a mais de três anos. 
A literatura examinada indica que os efeitos provocados pela inexistência ou fragilidade dos vínculos familiares podem ser agravados pela permanência prolongada da criança em ambiente institucional. Bronfenbrenner (2011) considera que, nessas circunstâncias, provavelmente são poucos os adultos com quem a criança poderá manter relação afetiva e duradoura, em razão da rotatividade imposta pelo sistema de turnos de trabalho e do atendimento despersonalizado, que são características próprias das instituições do tipo asilar, mesmo nos dias atuais.

Para Rizzini e Rizzini (2004), e Tarullo e Gunnar (2007), entre os efeitos nocivos que institucionalização precoce e prolongada pode trazer à criança, deve-se dirigir um olhar à ameaça real de ruptura dos vínculos com a família de origem e dificuldades existentes para a formação de novos laços afetivos, pois a convivência com adultos e coetâneos no cotidiano do abrigo embora seja intensa, muitas vezes não possibilita o contato físico afetuoso e não sugere espaço para a intimidade.

Em razão da existência de mecanismos mais eficazes de controle da sociedade sobre os ambientes coletivos de cuidado (creches, pré-escolas, abrigos, entre outros), quando a criança fica sob a responsabilidade de uma instituição de acolhimento infantil, costuma receber cuidados físicos relativamente adequados (há preocupação com a alimentação, a higiene e o trato de doenças comuns), mas emocionalmente indiferentes (existe a massificação, a despersonalização, a burocratização do atendimento social, que pode tornar impessoal e distante o contato com os cuidadores). Isso pode propiciar situações de deficiência cognitiva e danos emocionais que afetam de maneira decisiva o seu desenvolvimento, como explicam Rizzini e Rizzini (2004), Weber e Kossobudzki (1996).

Entretanto, segundo Sigal et al. (2003), o quoeficiente de inteligência das crianças com histórico de institucionalização nos primeiros anos de vida e de longa permanência na instituição, pode não ser gravemente comprometido em razão da permanência em instituições de abrigo, assim como a sua capacidade de ligar-se e apegar-se aos cuidadores e o seu senso de identidade. Para esses autores, é preciso considerar a influência de outros fatores que podem afetar o desenvolvimento humano (características pessoais, traços do temperamento, qualidade do cuidado institucional e do ambiente no período pósinstitucionalização, entre outras). Lembram ainda que, além desses fatores, outros relacionados às características do processo de acolhimento vivido por cada criança e suas implicações para o curso do seu desenvolvimento devem ser considerados.
As razões que justificaram a permanência da criança em instituições é um exemplo do que pode ter efeito nefasto para o desenvolvimento do indivíduo, especialmente quando entre outras razões a pobreza figura no quadro de razões que levaram à institucionalização da criança. Contudo, as razões apontadas para o acolhimento institucional nem sempre podem ser descritas como excepcionais, posto que o recrudescimento da pobreza entre famílias nos centros urbanos, a fragilidade das redes sociais de apoio aos pais e/ou responsáveis, a disseminação do consumo de drogas e da violência doméstica, devem ser reconhecidos como problemas e/ou características estruturais da sociedade brasileira (Rizzini e Rizzini, 2004).

Nesta pesquisa 40,41\% (2004) e 59,59\% (2009) das crianças foram encaminhadas para o abrigo como medida de proteção especial em razão de situações de crise, risco e dificuldades vividas por suas famílias. Nesses casos, uma conjunção de fatores motivou a decisão do acolhimento pelas autoridades competentes e até pelos próprios pais e/ou responsáveis.

Verificou-se que uma parte significativa dos casos examinados aponta para a existência de crianças que, entre outras situações consideradas de risco ao desenvolvimento nos anos iniciais, foram encontradas em local e horário impróprios à sua faixa de idade, muitas vezes sozinhas, ou, no máximo, na companhia de outras crianças - irmãos, amigos, vizinhos. Da mesma forma, foram relatados casos de negligência familiar que denunciaram a realidade de crianças deixadas sozinhas em casa, que não contavam com a atenção e os cuidados de um adulto responsivo às suas demandas, apresentando condições precárias de nutrição, higiene e saúde. Estes dados são particularmente importantes para estudiosos da primeira infância, porque a literatura afirma que nascer e crescer em um meio sociofamiliar que apresenta uma conjunção de fatores que levam à vulnerabilidade social da família e da criança (Barros et al. 2006), afeta o desenvolvimento do cérebro e prejudica a formação de ligações neurais subjacentes às aquisições que são esperadas nos primeiros anos de vida (Wiik et al., 2010).

Entre os casos examinados na instituição pesquisada, chama atenção o fato de que as crianças deram entrada nesta instituição em razão de atitudes vistas como negligência por parte de seus cuidadores primários, mas os dados coletados sugerem tratar-se frequentemente de um ambiente familiar pouco capaz de atender às necessidades infantis decorrentes das tarefas do desenvolvimento nesse período de maior sensibilidade e exigências mais complexas (Andrade et al., 2005; Barros et al., 2006) 
Além disso, resultados desta pesquisa guardam relação com os motivos apontados para o acolhimento institucional encontrados em estudos sobre a realidade dos abrigos e dos abrigados no Brasil (Cavalcante, 2008; IPEA, 2004; Morais et al.,2004; Serrano, 2008). No levantamento feito pelo IPEA (2004), em particular, fica claro que os motivos que justificam a institucionalização de crianças e adolescentes relacionam-se principalmente à condição de pobreza e vulnerabilidade social das famílias brasileiras (trabalho, escolaridade, renda, moradia, acesso a serviços básicos historicamente têm a marca da precariedade), como explicam Cavalcante et al. (2012).

Outro motivo que costuma justificar o acolhimento institucional, segundo a literatura sobre o tema e dados apresentados neste estudo, seria o fato de que crianças que passam a viver em instituições assim o fazem porque foram sistematicamente vítimas de agressão física e abuso sexual por parte dos pais e/ou responsáveis. Estudos mostram que a ocorrência de diferentes formas de abuso e violência contra a criança aparece relacionada à existência de situações de crise enfrentadas por grupos familiares de diferentes classes sociais, mas, supostamente, em contextos marcados pela pobreza este tipo de comportamento parental tem encontrado solo fértil para sua manifestação (Brancalhone et al., 2004; Habigzang et al., 2005; McCall, Groark, Fish, Harkins, Serrano e Gordon, 2010; Nelson, 2007; Scaramella et al., 2008; Wiik et al., 2010).

Adicionalmente, como parte dos resultados aqui relatados, menciona-se a dependência química dos pais e/ou responsáveis aparece como um dos motivos que justificou sobremaneira o acolhimento da criança. No levantamento nacional feito pelo IPEA (2004), 11,3\% das crianças e dos adolescentes que viviam em abrigos no Brasil foram acolhidos por esse motivo específico. Na região Norte, este percentual era de 7,1\%.

Entre as situações de crise que funcionam como fatores de risco para o abuso infantil, segundo Dozier et al. (2012), Habigzang et al. (2005) e Lewandowski, et al. (2002), destacam-se o desemprego prolongado de qualquer um dos cônjuges (sinônimo de impotência, ócio, insegurança, instabilidade financeira), as separações conjugais (sem definição clara das responsabilidades devidas a partir de então aos filhos) e o uso abusivo do álcool e outras drogas por parte dos pais e/ou responsáveis.

\section{CONSIDERAÇÕES FINAIS}

Ao se caracterizar as duas amostras de crianças atendidas em um espaço de acolhimento com base no perfil de seus pais e os motivos que justificaram a aplicação desta medida sociojurídica de proteção à infância, compreende-se a relevância de estudos como este que possibilitam apontar aspectos estruturantes deste contexto ecológico de desenvolvimento. E que, não por coincidência, retratam igualmente aspectos descritores do modo de vida de parcela expressiva das famílias de crianças que vivem no país, nos primeiros anos de vida.

Como se procurou mostrar, os motivos que levaram tantas crianças ao acolhimento institucional foram os mais variados, contudo, ao se relacionar estes dados com características que integram o perfil das famílias consideradas em situação excepcional, verificou-se que grande parte dos pais encontrava-se em situação de notória pobreza, assim como amplas parcelas da população que ainda vive no Brasil. Portanto, conhecer como essa condição de vulnerabilidade social se apresentou nesta população específica, em 2004 e 2009, considera-se que é parte do compromisso que devem ter os pesquisadores do desenvolvimento que ocorre na primeira infância, principalmente com a compreensão dos efeitos derivados das situações de privação que caracterizam a pobreza e suas condições típicas.

Mesmo sabendo que a pobreza é expressão direta das relações sociais vigentes na sociedade, a compreensão deste fenômeno não pode estar restrita às privações materiais, ainda que as condições socioeconômicas sejam fatores determinantes no nível de acesso da criança às oportunidades que permitem um desenvolvimento saudável e rico em possibilidades humanas. Nascer e viver sob o signo da pobreza remete à necessária atenção com as múltiplas formas de privação e/ou limitações de ordem emocional, material ou social, que podem atingir gravemente a criança nesses períodos de maior sensibilidade em termos desenvolvimentais.

Os resultados destacaram que, na maioria dos casos analisados, havia indícios de que as crianças encaminhadas à instituição não recebiam os cuidados adequados no meio familiar. Além disso, evidenciaram a existência de situações frequentes de negligência e abandono por parte dos pais e/ou responsáveis. Todavia, os mesmos dados levam a pensar que a adoção de medidas de enfrentamento da pobreza pensadas em uma perspectiva ecológica - ou seja, envolvendo estruturas micro e macrossistêmicas - poderia reduzir significativamente o número de crianças que passam os anos iniciais da infância em instituições, porque faltam ações de apoio aos pais na execução de suas funções parentais fundamentais, conforme discute a Rede Nacional Primeira Infância (2010). 
Finalmente, é preciso destacar que qualquer medida ou instrumento no campo das políticas públicas centradas na promoção do desenvolvimento na primeira infância deve se apoiar em dados fidedignos e atualizados sobre a condição sociofamiliar das famílias de crianças em diferentes contextos ecológicos. Esta é a condição fundamental para que tais medidas e intervenções possam ser acompanhadas e avaliadas em seus efeitos para o desenvolvimento infantil. Afinal, investigar as características sociofamiliares de determinada população infantil deve ser um objetivo a ser perseguido pelos pesquisadores de forma sistemática na atualidade, por viabilizar a comparação de análises compondo uma série histórica, a projeção de resultados esperados para o futuro, o significado de aquisições e déficits em diferentes contextos ecológicos. E isso vale para a compreensão da realidade infantil na instituição pesquisada e para conhecer as crianças institucionalizadas que vivem no Brasil e outros países do mundo. Tal situação nos remete à tarefa de propor e acompanhar o planejamento e a atuação dos responsáveis pela gestão dessas informações, objetivando minimizar lacunas, imprecisões e vieses na leitura de quadros dessa realidade sociofamiliar.

\section{REFERÊNCIAS}

Andrade, S. A., Santos, D. N., Bastos, A. C., Pedromônico, M. R. M., Almeida-Filho, N., \& Barreto, M. L. (2005). Ambiente familiar e desenvolvimento cognitivo infantil: Uma abordagem epidemiológica. Revista de Saúde pública, 39, 606-611.

Barros, R. P., Carvalho, M., \& Franco, S. (2006). Pobreza multidimensional no Brasil. Rio de Janeiro: IPEA.

Beckett, C., Maughan, B., Rutter, M., Castle, J., Colvert, E., Groothues, C., Kreppner, J., Stevens, S., O'Connor, T.G., \& Sonuga-Barke, E. J. S. (2006). Do the effects of early severe deprivation on cognition persist into early adolescence? From the English and Romanian Adoptees Study. Child Development, 77, 696-711.

Bernal, E. M. B. (2004). Arquivos do abandono. Experiências de crianças e adolescentes internados em instituições de Serviço Social de Menores de São Paulo (1938-1960). São Paulo: Cortez.

Brancalhone, P. G., Fogo, J. C., \& Williams, L. C. A. (2004). Crianças Expostas à Violência Conjugal: avaliação do desempenho acadêmico. Psicologia: Teoria e Pesquisa, 20, 113-117.

Bronfenbrenner, U. (2011). Bioecologia do desenvolvimento humano: tornando os seres humanos mais humanos. Porto Alegre: Artmed.

Calamante, A. J. (2007). Saneamiento básico, agua potable y salud pública. In Colombo, J. A. (Org.). Pobreza e desenvolvimento infantil. Uma contribuição multidisciplinar (pp. 327-353). Buenos: EDUFPA.

Cavalcante, L. I. C. (2008). Ecologia do cuidado: interações entre a criança, o ambiente, os adultos e seus pares em instituição de Abrigo. Tese de doutorado não publicada. Universidade Federal do Pará, Programa de Pós-Graduação em Teoria e Pesquisa do Comportamento. Universidade Federal do Pará, Belém.
Cavalcante, L. I. C., Magalhães, C. M. C., \& Costa, L. N. (2012). Caretaking behavior among siblings in children's shelters. Psicologia: Reflexão e Crítica (UFRGS. Impresso), 25, 165-173.

Cavalcante, L. I. C., Magalhães, C. M. C., \& Pontes, F. A. R. (2007). Institucionalização precoce e prolongada de crianças: discutindo aspectos decisivos para o desenvolvimento. Aletheia, $25,20-34$

Dozier, M., Zeanah, C., Wallin, A. R., \& Shauffer, C. (2012). Institutional care for young children: rewiew of literature and policy implications. Social Issues and Policy Review, 6(1), $1-25$.

Habigzang, L. F., Koller, S. H., Azevedo, G. A., \& Machado, P. X. (2005). Abuso sexual infantil e dinâmica familiar: aspectos observados em processos jurídicos. Psicologia: Teoria e Pesquisa, 21(3), 341-348.

Halpern, R., \& Figueiras, A. C. M. (2004). Influências ambientais na saúde mental da criança. Jornal de Pediatria, 80, 104-110.

Instituto de Pesquisa Econômica Aplicada - IPEA. (2004). Levantamento nacional de abrigos para crianças e adolescentes da rede $S A C$. Retirado de http://.www.ipea.gov.br.

Lewandowski, D. C., De Antoni, C., Koller, S. H., \& Piccinini, C. A. (2002). Paternidade na adolescência e os fatores de risco e de proteção para a violência na interação pai-criança. Interações, 13(7), 11-100.

McCall, R. B., Groark, C. J., Fish, L., Harkins, D., Serrano, G., \& Gordon, K. (2010). A socioemotional intervention in a latin american orphanage. Infant Mental Health Journal, 31(5), 521-542.

Morais, N. A., Leitão, H. S., Koller, S. H., \& Campos, H. R. (2004). Notas sobre a experiência de vida num internato: aspectos positivos e negativos para o desenvolvimento dos internos. Psicologia em Estudo, 3, 379-387.

Nelson, C. A. (2007). A neurobiological perspective on early human deprivation. Child Development Perspective, 1(1), 13-18.

Paiva, G. S., Lima, A. C. V. M. S., Lima, M. C., \& Eickmann, S. H. (2010). The effect of poverty on developmental screening scores among infants. São Paulo Medicinal Journal, 128, 276-283.

Rede Nacional Primeira Infância. (2010). Plano Nacional pela Primeira Infância. Brasília, DF: Autores.

Rizzini, I., \& Rizzini, I. (2004). A Institucionalização de crianças no Brasil: percurso histórico e desafios presentes. Rio de Janeiro: Ed. PUC-Rio/UNICEF/CIESPI.

Roy, P., \& Rutter, M. (2006). Institutional care: associations between inattention and early reading performance. Journal of Child Psychology and Psychiatry, 41, 480-487.

Scaramella, L. V., Neppl, T. K., Ontai, L. L., \& Conger, R. D. (2008). Consequences of Socioeconomic Disadvantage across Three Generations: Parenting Behavior and Child Externalizing Problems. Journal of Family Psychology, 22(5), 725-733.

Serrano, S.A. (2008). O abrigamento de crianças de zero a seis anos de idade em Ribeirão Preto: Caracterizando esse contexto. Tese de doutorado não publicada. Universidade de São Paulo, Ribeirão Preto.

Sigal, J., Perry, J. C., Rossignol, M. I., \& Ouimet, M. C. (2003). Unwanted infants: psychological and physical consequences of inadeuate orphanage care 50 years later. American Journal of Orthopsychiatry, 73, 3-12.

Siqueira, A. C., \& Dell'Aglio, D. D. (2006). O impacto da institucionalização na infância e na adolescência: uma revisão da literatura. Psicologia e Sociedade, 18, 71-80.

Tarullo, A. R., \& Gunnar, M. R. (2007). False belief and emotion understanding in post-institutionalized children. Social Development, 16(1), 57-78. 
Vegas, E., \& Santibáñez, L. (2010). América Lati La promesa Del desarrollo en La primera infância en América Latina y El Caribe. Washingto-DC, Bogotá, Colômbia: Banco Mundial en coedición con Mayol Ediciones S.A.

Weber, L. N. D., \& Kossobudzki, L. H. M. (1996). Filhos da solidão. institucionalização, abandono e adoção. Curitiba: Governo do Estado do Paraná.

Wiik, K. L., Loman, M. M., Ryzin, M. J. V., Armstrong, J. M., Essex, M. J., Pollak, S. D., \& Gunnar, M. R. (2010). Behavioral and emotional symptoms on post-institutionalized children in middle childhood. Journal of Child Psychology and Psychiatry, 52(1), 56-63.
Autores:

Lília Iêda Chaves Cavalcante - Universidade Federal do Pará.

Celina Maria Colino Magalhães - Universidade Federal do Pará. Bolsista de Produtividade CNPq.

Daniela Castro dos Reis - Universidade Federal do Pará.

Endereço para correspondência:

Lília Iêda Chaves Cavalcante

Programa de Pós-Graduação em Teoria e Pesquisa do Comportamento

Rua Augusto Corrêa, 01 - Campus Universitário do Guamá

CEP 66075-110 Belém, PA, Brasil

E-mail: liliaccavalcante@gmail.com

Recebido em: 18.02.2013.

Aceito em: 08.01.2014 